\title{
Fiscal Behavior Volatility, Economic Growth, and Urban-Rural Income Disparity
}

\author{
Yufeng WANG \\ School of International Trade and Economics, University of International Business and Economics, \\ Beijing 100029, China \\ E-mail:51dodo@163.com \\ Shulin LIU \\ School of International Trade and Economics, University of International Business and Economics, \\ Beijing 100029, China \\ E-mail: slliu@uibe.edu.cn
}

\begin{abstract}
Fiscal behavior of local governments has great volatility in China, especially in the period of economic transition. This paper estimates fiscal behavior volatility by making regression analysis of panel data of 30 provinces from 1994 to 2011. Then we establish a dynamic panel model to study the direct and indirect impact of the fiscal behavior volatility on the urban-rural income disparity. Empirical results show that urban-rural income disparity has nonlinear relationship with economic growth and financial development and that fiscal behavior volatility expands the urban-rural income disparity directly and indirectly. The larger fiscal behavior volatility comes greater urban-rural income disparity. We also find that the urban-rural income disparity is further enlarged through dual economic structure. If one of the economic growth and financial development is fixed, the other one has an inverted U-shaped relationship with urban-rural income disparity.
\end{abstract}

Keywords urban-rural income disparity; fiscal behavior volatility; economic growth; financial development; inverted U-shaped relationship

\section{Introduction}

China has become one of the countries with largest income gap in the world although it has made remarkable economic achievements, and the expansion of urban-rural income disparity is one of the most important impact factors ( $\mathrm{Lin}$, et $\mathrm{al}^{[1]}$ ). What are the main determinants of urban-rural income disparity? How can government improve the environment to reduce urban-rural income disparity? The answers to these questions have changed fundamentally over the last decades and they are keys in the period of economic transition. More recently, the consensus on the determinants of urban-rural income disparity has focused on policy volatility, especially the fiscal behavior volatility.

The important responsibility of government is promoting harmonious economic development and maintaining social stability. At the same time, the policy fluctuates because of economic

Received December 11, 2013, accepted February 25, 2014

Supported by Project of Joint Training Graduate Students at Home and Abroad in University of International Trade and Economics 
fluctuations or discretionary policy. Acemoglu, et al. ${ }^{[2]}$ and Easterly ${ }^{[3]}$ found that the macro policy fluctuation had explanatory power for economic growth and income between countries, since then, more scholars started on the study of policy behavior volatility, but there had been no suitable model to measure the volatility. Fatas and Mihov ${ }^{[4]}$ measured the policy behavior volatility by regression analysis method and presented evidence that policy volatility exerted a strong and direct negative impact on growth. In a cross-section of 91 countries, policy volatility emerged as a key determinant of macroeconomic performance. An increase in the volatility of fiscal policy corresponding to one standard deviation in the sample reduced long-term economic growth by about $0.75 \%$. Afonso ${ }^{[5]}$ decomposed the fiscal behavior into three parts including discretion, persistence and volatility on the basis of the data from the 132 countries.

Historical data of economic growth seems to suggest an inverted U-shaped Kuznets ${ }^{[6]}$ curve for the relationship between economic growth and income disparity. Yang and Zhou ${ }^{[7]}$ found that there was a V-shaped change after economic reform in the late 1970s between urban-rural consumption and income.

Financial development is also one impact factor of urban-rural income disparity, however, research conclusion is substantially different due to the different research methods. Clarke ${ }^{[8]}$ shows that there is negative correlation between financial development and income distribution disparity based on global data. Galor and Zeira ${ }^{[9]}$ suggest that there is no inverted U-shaped relationship between financial development and urban-rural income disparity, especially in the imperfect financial market, Wang ${ }^{[10]}, \mathrm{Ye}^{[11]}$ and $\mathrm{Sun}^{[12]}$ have the same research results.

Apart from the above two factors, other factors might also have impact on urban-rural income disparity. Some factors impact urban-rural income disparity negatively, like urbanization (Lu, et al. ${ }^{[13]}$, Yao ${ }^{[14]}$ ), human capital investment (Chen, et al.. ${ }^{[15]}$ ), and the government fiscal expenditure structure (Lu, et al. $\left.{ }^{[13]}\right)$. However, Some factors impact urban-rural income disparity positively, such as dual economic structure $\left(\mathrm{Guo}^{[16]}\right)$ and open economy (Wei ${ }^{[17]}$ ). This paper will consider the above factors, economic growth, financial development, the dual economic structure, urbanization, opening and financial behavior volatility for the influence factors of urban-rural income disparity.

Regarding to the impact factors of urban-rural income disparity, there are three different pieces of empirical evidence that call into the importance of these factors. First, policy behavior volatility variable become significant in the regressions where a large number of variables are tested as determinants of long term performance. Second, many scholars studied the influence of fiscal behavior to urban-rural income disparity, which caused the question of the influence of fiscal behavior volatility to it. And finally, as to other factors, such as economic growth, financial development, the dual economic structure, urbanization and opening, this paper considers them because they are important impact factors that many scholars have verified them, but the research results are substantially different due to the different research methods. Therefore, this paper combines them together to verify the previous results.

The difference between our paper and some of the previous papers is that this paper takes fiscal behavior volatility as one of the impact factors of urban-rural income disparity for the first time, which makes up for the research gap in this field. This paper studies not only the direct impact of fiscal behavior volatility on urban-rural income disparity, but also the indirect 
effects through the dual economic structure of China. The second difference is that this paper combines the economic growth and financial development together, which are always separated in the previous studies, to get the impact of one variable on the control of the other.

The result shows that fiscal behavior volatility has a negative effect on urban-rural income disparity. This paper also found that economic growth and financial development, as two important impacting factors, show inverted U-shaped relationship when the other variable is fixed. Namely, economic growth and financial development will help to narrow the urban-rural income disparity in the long term.

The following section describes the empirical strategy and reports the results for the effect of fiscal behavior volatility on urban-rural income disparity. Section 2 elaborates the measurement of fiscal behavior volatility and the sample data. Our key result, that fiscal behavior volatility negatively affects urban-rural income disparity and the inverted U-shaped relationship between economic growth, financial development and urban-rural income disparity, is reported in section 3 with the robustness test. The paper ends with a discussion of the conclusion and remarks in the final section.

\section{Fiscal behavior volatility}

\subsection{Data description}

One of the hypothesis (hypothesis I) is that policy volatility exerts a negative impact on urban-rural income disparity through direct and indirect effect. This paper chooses panel data of 30 provinces from 1994 to 2011 according to the data availability. Base data of urbanization (UN), open economy (OP), financial development (FD) are from the regional statistical yearbook from 1995 to 2012, while GDP, urban-rural income disparity (y) and dual economic structure (S) come from the China statistical yearbook in 2012 and CEINET database. This paper changes these variables into real variables based CPI of 1994 to eliminate the influence of inflation. Table 1 reports summary statistics of the sample.

Table 1 Summary statistics of sample

\begin{tabular}{clccccc}
\hline variable & variable name & observations & mean & S.D. & maximum & minimum \\
\hline y & urban-rural income disparity & 540 & 2.908 & 0.698 & 5.6 & 1.6 \\
S & dual economic structure & 540 & 5.683 & 2.948 & 20.2 & 1.64 \\
FBV & fiscal behavior volatility & 540 & 12.809 & 0.512 & 14.52 & 11.78 \\
UN & urbanization & 540 & 0.323 & 0.16 & 0.89 & 0.12 \\
GDP & economic growth & 540 & 1.54 & 1.49 & 8.52 & 0.15 \\
OP & open economy & 540 & 18.67 & 23.4 & 91.2 & 0.81 \\
FD & financial development & 540 & 2.33 & 0.93 & 7.63 & 0.82 \\
\hline
\end{tabular}

Note: OP and FD are in percentage. S.D. is the standard deviation.

\subsection{Measurement of fiscal behavior volatility}

Fiscal behavior mainly includes the fiscal revenue policy and fiscal expenditure policy. In general, there are three measures of fiscal behavior volatility: first, standard deviation of fiscal policy variables. Second, conditional variance through GARCH model (Henisz, et al. ${ }^{[18]}$ ), but 
this method is usually used for policy changes caused by volatility. While the above two methods of measurement may cause inaccurate estimation results because they don't exclude the policy fluctuations caused by economic fluctuations. Third, remaining residual volatility by regression analysis. The fiscal behavior is decomposed into three parts including discretion, persistence and volatility. Excluding discretion and persistence, the remaining residual volatility is the fiscal behavior volatility. In this section we construct a measure according to the third method based on Fatas and Mihov( $\left.{ }^{[4,19]}\right)$, Afonso, et al. ${ }^{[5]}$.

In order to distinguish the components of responsiveness, persistence and discretion of government spending and revenue, we estimate with the following regressions:

$$
\begin{aligned}
& \ln \left(G_{i t}\right)=\alpha_{i}^{G}+\beta_{i}^{G} \ln \left(G A P_{i t}\right)+\gamma_{i}^{G}\left(\ln \left(G_{i, t-1}\right)\right)+\delta_{i}^{G} X_{i t}+\varepsilon_{i t}^{G} \\
& \ln \left(R_{i t}\right)=\alpha_{i}^{R}+\beta_{i}^{R} \ln \left(G A P_{i t}\right)+\gamma_{i}^{R}\left(\ln \left(R_{i, t-1}\right)\right)+\delta_{i}^{R} X_{i t}+\varepsilon_{i t}^{R}
\end{aligned}
$$

where $G$ is real government spending, $R$ is real government revenue and $X$ is a set of controls including a time trend, the level value and square of inflation.

GAP is the regional output GAP, the values can be estimated by HP filter method:

$$
\min \sum_{i=1}^{T}\left(\ln Y_{i}-\ln Y_{i}^{*}\right)^{2}+\lambda \sum_{t=2}^{T-1}\left[\left(\ln Y_{t+1}^{*}-\ln Y_{t}^{*}\right)-\left(\ln Y_{t}^{*}-\ln Y_{t-1}^{*}\right)\right]^{2}
$$

The natural logarithm of real output $\ln Y_{i}$ is decomposed into trend components (the natural logarithm of potential output $\ln Y_{i}^{*}$ ) and periodic components (the output gap $\ln Y_{i}-\ln Y_{i}^{*}$ ). The smoothing parameter $\lambda=25$ by using the annual data.

When it comes to the analysis of fiscal behavior volatility, we focus on fiscal expenditure policy. Because fiscal revenue policy in China is relatively stable, while fiscal expenditure policy has greater volatility, which leads to the structural imbalance of the central finance and local finance. And some studies indicate that the fiscal revenue policy has small impact on the income disparity, while transfer payments in government spending policy may expand the competitiveness and efficiency of the differences between regions $\left(\mathrm{Liu}^{[20]}\right)$.

Equation (1) is a variable coefficient and dynamic model, and will be estimated by GMM (Generalized the Methods of Moments) method using instrumental variables because of endogenous problem. We use two lags of output growth and lagged inflation as instruments. We get each regression residuals by grouping regression, the standard deviation of residual stands for fiscal behavior volatility, and will be carried out further the exponential regression. They all pass the correlation test of endogenous variable and relative to exogenous test of the residual.

\section{Empirical strategy}

In this section, this paper studies the direct and indirect effects of fiscal behavior volatility to urban-rural income disparity, and verifies one of the other hypothesis, there is a inverted U-shaped relationship between economic growth, financial development and urban-rural income disparity (hypothesis II).

\subsection{Regression model}

In recent years, many scholars have studied the impact factor of urban-rural income disparity from the perspective of dual economic structure, urbanization level, the level of economic growth 
and opening, the most significant impact factor is the urban-rural dual economic structure, including binary tax system, dual fiscal investment system, dual social security system, which lead to widen the urban-rural income disparity. At the same time, in order to study the nonlinear effects between economic growth, financial development and the urban-rural income disparity, their square are considered in the model. The regression model as follows:

$$
\begin{aligned}
y_{i t}= & \alpha+\beta_{1} y_{i t-1}+\beta_{2} S_{i t}+\beta_{3} F B V_{i} * S_{i t}+\beta_{4} F B V_{i}+\beta_{5} G D P^{2}+\beta_{6} F D^{2} \\
& +\gamma z_{i t}+\lambda_{t}+u_{i}+\varepsilon_{i t}
\end{aligned}
$$

where $y_{i t}$ is the urban-rural income disparity of the $i$ th provinces in time $t, S_{i t}$ and $F B V_{i}$ are dual economic structure and fiscal behavior volatility of local government, respectively. A series of control variables include economic growth (GDP), financial development (FD), level of urbanization (UN), open economy (OP); $\lambda_{t}$ is specific time fixed effect, which has nothing to do with the region; $u_{i}$ is fixed effect for particular region, which has nothing to do with the time.

\subsection{Results and discussion}

One problem of estimating model (4) using OLS is that the lagged dependent variable is endogenous to the fixed effects $\left(u_{i}\right)$, which will increase the estimated error. Thus, OLS estimates of this model will be inconsistent, even in the fixed or random effects settings, because would be correlated with the error term, $\epsilon$, even if the latter is not serially correlated. Firstdifference removes the individual effect $\left(u_{i}\right)$ and thus eliminates a potential source of bias. While, variables become endogenous when they are first differenced if they are not strictly exogenous, since the first-difference will be correlated with the error term. Following HoltzEakin, et al. ${ }^{[21]}$, Arellano and Bond ${ }^{[22]}$ developed a Generalized Method of Moments (GMM) estimator for linear dynamic panel data models that solves this problem by instrument variables: levels of the dependent and endogenous variables, lagged two or more periods; levels of the predetermined variables, lagged one or more periods. The exogenous variables can be used as their own instruments.

The results of system-GMM estimation of the model are shown in Table 2. Column (1) (4) give the basic estimation results of system-GMM, column (5) and (6) are the results by mixed regression and random effects, which are for the comparison and analysis. AR (1) and AR (2) results show that there is no second order autocorrelation between the residual error, Hansen test results show that the instrumental variable is effective, and the proposed system-GMM method is also effective.

The symbols of main explanation variable are consistent with rational expectations. There is a strong positive relationship between fiscal behavior volatility (FBV) and urban-rural income disparity. In addition to statistical significance, impact of fiscal behavior volatility on the urbanrural income disparity is quite considerable. From column (2), one point increase in the fiscal behavior volatility increases urban-rural income disparity by $0.193 \%$. Comparing with column (1) and (3), there is a weaker affect through the dual economic structure, but it is still a positive correlation. Coefficient of interactive items $\mathrm{FBV}^{*} \mathrm{~S}$ is positive, which instructs that the larger urban-rural income disparity is, the greater the volatility of financial behavior is, especially for the provinces with more obvious dual economic structure. 
Table 2 The results of system-GMM estimations

\begin{tabular}{|c|c|c|c|c|c|c|}
\hline \multirow[b]{2}{*}{ variable } & \multicolumn{4}{|c|}{ SYS-GMM } & \multirow{2}{*}{$\begin{array}{c}\text { POOL } \\
(5)\end{array}$} & \multirow{2}{*}{$\begin{array}{l}\mathrm{RE} \\
\text { (6) }\end{array}$} \\
\hline & (1) & $(2)$ & (3) & (4) & & \\
\hline \multirow[t]{2}{*}{ L.y } & $0.834^{* * *}$ & $0.858^{* * *}$ & $0.853^{* * *}$ & $0.855^{* * *}$ & - & - \\
\hline & $(0.035)$ & $(0.06)$ & $(0.019)$ & $(0.0407)$ & - & - \\
\hline \multirow[t]{2}{*}{$\mathrm{S}$} & $0.039^{*}$ & $0.026^{* * *}$ & $0.0446^{*}$ & $0.041^{* * *}$ & $0.114^{* * *}$ & $0.0504^{* *}$ \\
\hline & $(0.028)$ & $(0.0089)$ & $(0.019)$ & $(0.007)$ & $(0.0358)$ & $(0.0222)$ \\
\hline \multirow[t]{2}{*}{$\mathrm{FBV}^{*} \mathrm{~S}$} & $0.0037^{* *}$ & - & $0.00108^{* *}$ & - & $0.0015^{* * *}$ & $0.0611^{*}$ \\
\hline & $(0.005)$ & - & $(0.0037)$ & - & $(0.0031)$ & $(0.183)$ \\
\hline \multirow[t]{2}{*}{ FBV } & $0.021^{*}$ & $0.193^{*}$ & $0.079^{*}$ & $0.123^{*}$ & $0.501^{* * *}$ & $0.051^{* *}$ \\
\hline & $(0.026)$ & $(0.033)$ & $(0.018)$ & $(0.143)$ & $(0.104)$ & $(0.0415)$ \\
\hline \multirow[t]{2}{*}{ UN } & $-0.87^{* * *}$ & $-1.097^{*}$ & $-0.794^{* * *}$ & $-0.893^{* * *}$ & $-2.576^{* * *}$ & $-1.325^{* *}$ \\
\hline & $(0.302)$ & $(0.483)$ & $(0.204)$ & $(0.151)$ & $(0.657)$ & $(0.548)$ \\
\hline \multirow[t]{2}{*}{ GDP } & 0.0049 & 0.013 & $-0.022^{* *}$ & $-0.0181^{*}$ & -0.0099 & $0.187^{* * *}$ \\
\hline & $(0.046)$ & $(0.0384)$ & $(0.0105)$ & $(0.0119)$ & $(0.0772)$ & $(0.0414)$ \\
\hline \multirow[t]{2}{*}{ GDP2 } & $-0.0034^{*}$ & $-0.0032^{*}$ & - & - & $-0.00134^{* *}$ & $-0.0169^{* * *}$ \\
\hline & $(0.0074)$ & $(0.00407)$ & - & - & $(0.0105)$ & $(0.00659)$ \\
\hline \multirow[t]{2}{*}{ OP } & $0.000459^{*}$ & $0.000069^{*}$ & $0.00098^{*}$ & $0.000116^{*}$ & -0.00739 & $0.0022^{* * *}$ \\
\hline & $(0.0015)$ & $(0.0002)$ & $(0.0001)$ & $(0.00061)$ & $(0.00292)$ & $(0.00228)$ \\
\hline \multirow[t]{2}{*}{ FD } & 0.138 & $0.143^{*}$ & $0.07^{* * *}$ & $0.073^{* * *}$ & $0.859^{* * *}$ & $0.0398^{*}$ \\
\hline & $(0.0986)$ & $(0.0843)$ & $(0.0147)$ & $(0.0215)$ & $(0.199)$ & $(0.113)$ \\
\hline \multirow[t]{2}{*}{ FD2 } & $-0.00608^{*}$ & $-0.0107^{*}$ & - & - & $-0.0781^{* * *}$ & $-0.005^{*}$ \\
\hline & $(0.017)$ & $(0.00936)$ & - & - & $(0.0243)$ & $(0.0106)$ \\
\hline \multirow[t]{2}{*}{ Constant } & 0.0926 & 5.08 & 1.406 & 1.876 & -4.285 & 3.312 \\
\hline & $(2.928)$ & $(8.664)$ & $(1.831)$ & $(3.202)$ & $(3.525)$ & $(2.472)$ \\
\hline Observations & 510 & 510 & 510 & 510 & 540 & 540 \\
\hline Province & 30 & 30 & 30 & 30 & - & 30 \\
\hline \multirow[t]{2}{*}{$\operatorname{AR}(1)$} & -3.4113 & -3.1725 & -3.4706 & -3.4292 & - & - \\
\hline & $\mathrm{p}=0.0006$ & $\mathrm{P}=0.0015$ & $\mathrm{P}=0.0005$ & $\mathrm{P}=0.0006$ & - & - \\
\hline \multirow[t]{2}{*}{$\operatorname{AR}(2)$} & 1.0926 & 1.1111 & 1.0655 & 1.1449 & - & - \\
\hline & $\mathrm{P}=0.2746$ & $\mathrm{P}=0.2665$ & $\mathrm{P}=0.2867$ & $\mathrm{P}=0.2522$ & - & - \\
\hline Hansen & 26.82558 & 26.07216 & 27.36245 & 28.76421 & - & - \\
\hline Test & $\mathrm{P}=1.00$ & $\mathrm{P}=1.00$ & $\mathrm{P}=1.00$ & $\mathrm{P}=1.00$ & - & - \\
\hline
\end{tabular}

Note: Significance level at which the null hypothesis is rejected: ${ }^{* *}, 1 \% ;{ }^{* *}, 5 \%$, and ${ }^{*}, 10 \%$; t-statistics is in parenthesis.

Hypothesis II is verified by the estimation results in column (1) and (2), which shows that the coefficient of the square of economic growth (GDP2) and financial development (FD2) are significantly negative with the control another variable. There is a inverted U-shaped relationship between economic growth, financial development and urban-rural income disparity, 
which further verifies the Kuznets inverted U-shaped curve.

Dual economic structure (S) and opening (OP) are related positively to the urban-rural income disparity, these variables expand income disparity, which is consistent with the research conclusions of $\mathrm{Lu}$ and Chen ${ }^{[13]}$. Urbanization (UN) is negatively related to the income disparity, which means that the higher the level of urbanization, the smaller the urban-rural income disparity, which is also the cause of improvement of the urbanization in China. The income disparity is sustainable because the lag of income disparity is highly significant in the results.

Column (4) is a reduced version which removes all of the square and interaction of variables, however, there is also positive correlation between the fiscal behavior volatility and urban-rural income disparity, and the influence of the dual economic structure is more significant in urban and rural income gap. GDP is negatively related with the income disparity, the faster the economic growth, the smaller the income disparity, maybe it is inconsistent with status quo, but the conclusion is established in the long run (a combination of column (1) and column (2)). Financial development and urban-rural income disparity has significant positive correlation, financial development contributes $7.3 \%$ in expanding the income gap between urban and rural areas.

Column (5) and (6) are estimated results by static panel data regression method respectively. Due to model (4) the effect of individual FBV is needed to be estimated, in order to compare with the results of the first four columns, column (5) uses the method of mixed regression (POOL), and column (6) uses random effect. Results show that the fiscal behavior volatility and urban-rural income disparity are still positive correlation, and square and interaction of variables are significant negative.

\subsection{Robustness test}

In order to further test the robustness of the conclusion of fiscal behavior volatility effect on the urban-rural income disparity, this paper analyzes the robustness from the following two aspects. 1) Using the standard deviation of fiscal expenditure to depict fiscal behavior volatility. The results show that the symbols of explanatory variables and control variables and significance remain unchanged. At the same time, the Hansen test and the value of AR(1) and $\operatorname{AR}(2)$ also meet the requirements, which shows that there is a positive correlation between fiscal behavior volatility and urban-rural income disparity, namely the greater the financial behavior volatility, the greater the income gap between urban and rural areas. And the square of the economic growth and financial development are significantly negative, which shows the inverted U-shaped curve relationship between the financial behavior volatility and urban-rural income disparity. 2) By increasing the annual virtual variable control for the year effects, and the empirical result is consistent with the prior.

\section{Conclusions}

This paper provides an empirical study on the decomposition of fiscal policy into three characteristics: volatility, persistence and discretion by regression analysis, and then takes fiscal behavior volatility as one of the impact factors of urban-rural income disparity considering the nonlinear relationship between economic growth, financial development and urban-rural income disparity. The results documented in this paper firstly show that there is positive correlation 
between fiscal behavior volatility and urban-rural income disparity, namely the greater the financial behavior volatility is, the greater the income gap between urban and rural areas is. Secondly, the fiscal behavior volatility expands urban-rural income disparity directly and indirectly through binary structure. We also find that the urban-rural income disparity is more enlarged through dual economic structure. If one of the economic growth and financial development is fixed, the other one has an inverted U-shaped relationship with urban-rural income disparity.

From a policy perspective, fiscal behavior volatility has adverse effects on the urban-rural income disparity, therefore, it should not be neglected to reduce the local fiscal volatility behavior for narrowing the income gap between urban and rural areas. For instance, longer term budgetary issues, adjustment of fiscal expenditure structure, all these channels are likely to increase the fiscal volatility, and then expand the urban-rural income disparity. The frequency of local government fiscal policy conversion between different states is very high, high frequency volatility causes great uncertainty economic decision, which distorts the decision-making behavior, and decreases the efficiency of social resource allocation and social welfare. Therefore, government should further strengthen the regulation of local fiscal behavior and increase constraints for the behavior of local government to reduce volatility in economic transition period. Besides, another policy implication stems from the fact that urban-rural income disparity is greater with the economic and financial development in the short term. However, there is inverted U-shaped relationship between economic growth, financial development and urban-rural income disparity in the long term, which shows that widening income gap is inevitable.

The discretion of local government tends to cause fluctuations of fiscal policy, then expands the income gap between urban and rural areas. Therefore, government should make fiscal policy by rules as far as possible no matter what the policy goal is. Since it is inevitable to widen income gap between urban and rural areas in the economic development process, local governments should try to avoid too much fiscal policy volatility. Most of local governments make fiscal policy by discretion rather then by rules. United States, Britain and the countries in euro zone have adopted certain fiscal policy rules, which has good policy effect. Therefore, the government should make fiscal policy rules as soon as possible according to the economic situation.

\section{References}

[1] Lin Y F, Cai F, Zhou L. Regional gap analysis in economic transformation period in China[J]. Journal of Economic Research, 1998, 6(2): 3-10.

[2] Acemoglu D, Johnson S, Robinson J. Institutional causes, macroeconomic symptoms: Volatility, crises and growth[J]. Journal of Monetary Economics, 2003, 10(2): 49-123.

[3] Easterly W. National policies and economic growth: A reappraisal[M]. Handbook of Economic Growth, 2005, 1(A): 1015-1059.

[4] Fatas A, Mihov I. The case for restricting fiscal policy discretion[J]. The Quarterly Journal of Economics, 2003, 118(4): 1419-1447.

[5] Afonso A, Agnello L, Furceri D. Fiscal policy responsiveness, persistence, and discretion[J]. Public Choice, 2010, 145(14): 503-530.

[6] Kuznets S. Economic growth and income inequality[J]. American Economic Review (Nashville), 1955, 45(1): 1-28. 
[7] Yang D T, Zhou H. Rural and urban disparity and sectoral labour allocation in China[J]. Journal of Development Studies, 1999, 35(8): 105-133.

[8] Clarke G R G, Zou H, Xu L C. Finance and income inequality: Test of alternative theories[M]. World Bank, 2003.

[9] Galor O, Zeira J. Income distribution and macroeconomics[J]. The Review of Economic Studies, 1993, 60(1): 35-52.

[10] Wang Z, Lu Z Y. The rural financial development and urban-rural income gap - Empirical study based on the dynamic panel provincial data in China[J]. Journal of Finance and Economics, 2011, 7(4): 54-63.

[11] Ye Z Q, Chen X D. Can financial development reduce the income gap between urban and rural areas? Evidence from China[J]. Journal of Financial Research, 2011, 2: 42-56.

[12] Sun Y Q, Wan Y L. Financial development and opening and income gap in urban and rural area [J]. Journal of Financial Research, 2011, 1: 28-39.

[13] Lu M, Chen Z. Urbanization, economic policy and urban income gap between urban and rural areas[J]. Journal of Economic Research, 2004, 6: 51-58.

[14] Yao Y J. Informal regional differences of financial development and economic growth[J]. Study of Finance and Economics, 2009, 12: 129-139.

[15] Chen B K, Zhang P F, Yang N D. The government investment in education, human capital investment and income gap between urban and rural areas in China[J]. Management World, 2010, 1: 36-43.

[16] Guo G F, Liu M H. The research on income gap between urban and rural areas[J]. Journal of Economic Issues, 2007, 2(4): 85-87.

[17] Wei S J, Yi W. Globalization and inequality: Evidence from within China[J]. NBER Working Paper, 2001, No. 8611.

[18] Henisz W J. Political institutions and policy volatility[J]. Economics and Politics, 2004, 16(1): 1-27.

[19] Fatas A, Mihov I. Policy volatility, institutions and economic growth[M]. Centre for Economic Policy Research, 2005.

[20] Liu W. The analysis of structure characteristics of fiscal expenditure and fiscal revenue policy in China[J]. Journal of Finance and Economy, 2012, 10(1): 5-15.

[21] Holtz-Eakin D, Newey W, Rosen H S. Estimating vector autoregressions with panel data[J]. Econometrica: Journal of the Econometric Society, 1988, 34(6): 1371-1395.

[22] Arellano M, Bond S. Some tests of specification for panel data: Monte Carlo evidence and an application to employment equations[J]. The Review of Economic Studies, 1991, 58(2): 277-297. 